\title{
Mccleery's Syndrome the Overlooked Cause of Swollen Upper Limb, Completion Venoplasty is The Key Word for Successful Surgical Decompression
}

\author{
Ahmed K. Allam 1,3,4*, Mohamed Ismail Mohamed Ismail ${ }^{2,3,4}$, Mohamed Abd El-Monem Abd El-Salam Rizk ${ }^{2,3}$ \\ ${ }^{1}$ General Surgery Department, Benha University Hospitals, Benha, Egypt. \\ ${ }^{2}$ Vascular Surgery Department, Ain Shams University Hospitals, Egypt. \\ ${ }^{3}$ Vascular Surgery Department, Wadi El-Neel Hospital, Egypt. \\ ${ }^{4}$ General Surgery Department, Vascular Surgery Unit, Police Academy Hospital, Egypt. \\ *Corresponding author: Mohamed Abd El-Monem Abd El-Salam, Mobile: (+20) 01222310844,
}

Email: abu_elarzak@yahoo.com

\begin{abstract}
Background: Venous thoracic outlet syndrome (VTOS) is the second most presenting pattern of thoracic outlet syndrome (TOS). Non thrombotic VTOS swollen upper limb is usually overlooked by many surgeons. When there is chronic intermittent arm swelling that is associated with discoloration that worsen with overhead arm movement, McCleery's syndrome is more likely.

Objective: We present the results of our treatment strategy of McCleery's syndrome consisting of para-clavicular approach for thoracic outlet decompression (PCA-TOD), external venolysis, and combined surgical decompression with or without routine completion venoplasty.

Patients and methods: A retrospective analysis of the data of twenty-three patients who presented from January 2016 to February 2021 with chronic intermittent arm swelling, we divided the patients into two groups, group (A): 13 patients who underwent surgical decompression alone and follow up. Group (B): 10 patients who underwent surgical decompression associated with Intraoperative venography and balloon angioplasty. Results: In group (A) complete symptomatic resolution was achieved in 6/13 (46.2\%) patients, secondary endovenous intervention was required in 7 $(53.8 \%)$ patients due to residual symptoms, postoperative average residual arm circumference difference was $0.92 \pm$ $0.86 \mathrm{~cm}$ with a statistically significant difference in favor to group $(\mathrm{B})(\mathrm{P}$ value $=0.0274)$. In group (B) complete symptomatic cure achieved in 10/10 (100\%) patients with statistically highly significant difference favoring to group (B) $(\mathrm{P}$ value $=0.0075)$.

Conclusion: From our results, completion angioplasty of surgically decompressed axillo-subclavian venous segment added a significant cure and symptoms improvement for patients with McCleery's syndrome and could be considered as a primary therapy in conjunction with surgical decompression.
\end{abstract}

Keywords: McCleery's syndrome, Para-clavicular approach, Venoplasty.

\section{INTRODUCTION}

Venous thoracic outlet syndrome (VTOS) term is dedicated to the group of symptoms caused by squeezing of the subclavian vein between the clavicle and the first rib at the costoclavicular space (nutcracker like effect) in the thoracic outlet ${ }^{(\mathbf{1})}$. Mostly this squeeze is augmented by an abnormaly inserted costoclavicular ligament and/or hypertrophy of the scaleneus anterior muscle and/or subclavius muscle that narrow(s) the thoracic inlet ${ }^{(2)}$. There is some confusion about the nomenclature describing this condition. This confusion arises from variation of patients' symptoms and their associated pathology classifying VTOS into two main patterns. Compression and thrombosis of the axillo-subclavian venous segment are quite frequently referred to as effort thrombosis or Paget-Schroetter syndrome. There is a subset of patientscomplaining of symptoms that worsen with the arm being in overhead position, but without thrombosis, which is termed intermittent obstruction or McCleery syndrome ${ }^{(3)}$.

It is essential to differentiate patients presenting with McCleery syndrome from those with neurogenic TOS. Arm swelling is a frequent component of McCleery syndrome and is absent from neurogenic TOS.
Pain, numbness and tingling are common symptoms to both syndromes ${ }^{(4)}$.

Patients who have VTOS are thought to be at risk for developing upper limb deep venous thrombosis because there is compression of subclavian vein between the clavicle and the first rib, which acts as a permissive lesion and should undergo definitive treatment with first rib resection and scalenectomy ${ }^{(1)}$. The lack of much published articles concerned with McCleery syndrome could be explained by the unpopularity of its symptoms due to its intermittent behavior. So, the aim of our study was to describe the peculiar characteristics of patients presenting with McCleery syndrome and to evaluate the outcomes of those underwent first rib resection and scalenectomy with/without axillo-subclavian venous segment angioplasty.

\section{PATIENTS AND METHODS}

We conducted our retrospective analysis of prospectively collected data of 23 patients who were operated upon for first rib resection and complete surgical decompression, we analysed all patients admitted to Vascular Surgery Units/Departments of included centres from January 2016 to February 2021 at Benha University Hospital, Ain Shams University This article is an open access article distributed under the terms and conditions of the Creative Commons Attribution (CC BY-SA) license (http://creativecommons.org/licenses/by/4.0/) 
Hospitals, Wadi El-Neel Hospital, Police Academy Hospital, Egypt. Patients' data consisted of the demographic and clinical characteristics of patients, including their patient history, clinical presentation, postoperative complications, and follow-up information. All patients went through our evaluation stepladder process, started with patient history and symptoms analysis, complete physical examination including three manoeuvres to support our diagnosis:

- Rotation of the neck and tilting of the head to the opposite side to elicit pain in the affected arm.

- The upper limb tension test in which the patient first abducts both arms to 90 degrees with the elbows in a locked position, dorsiflexes the wrists, and finally tilts the head to the side. Each subsequent step

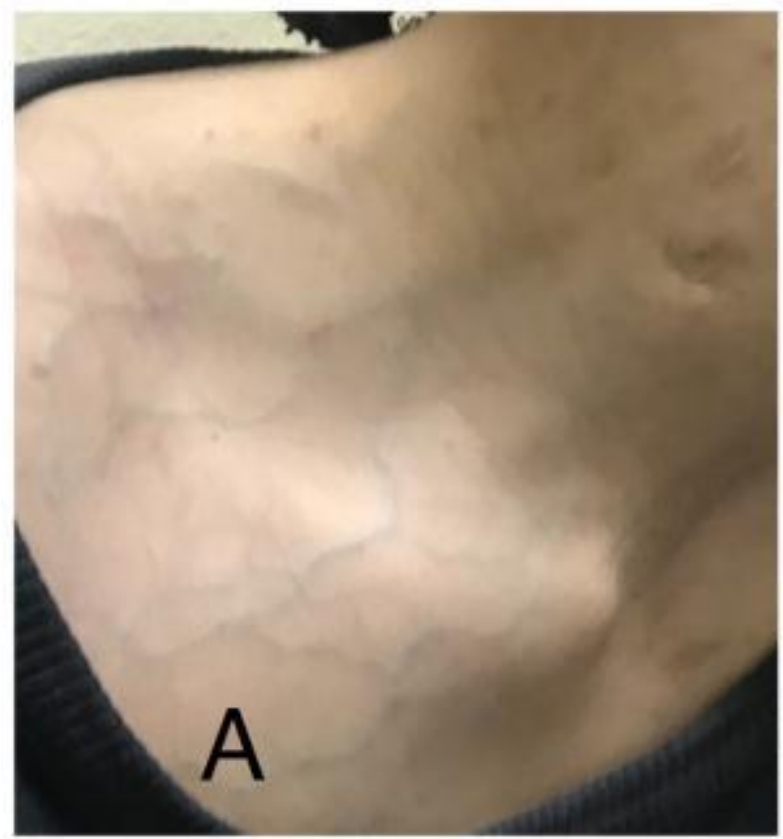

imparts greater traction on the brachial plexus and squeezes the subclavian vein, with the first two positions causing discomfort on the ipsilateral side and the head tilt position causing pain on the contralateral side ${ }^{(5)}$.

- The elevated arm stress test during which the patient raises both arms directly above the head and repeatedly opens and closes the fists ${ }^{(5)}$.

Inspection was done as a part of the patient evaluation for evidence chest wall dilated venous collaterals, as shown in Figure (1), and to determine the level of arm edema and degree of upper limb circumference difference in comparison to the asymptomatic contralateral limb at the level of the wrist, $5 \mathrm{~cm}$ below the elbow, and mid arm using a measurement tape.

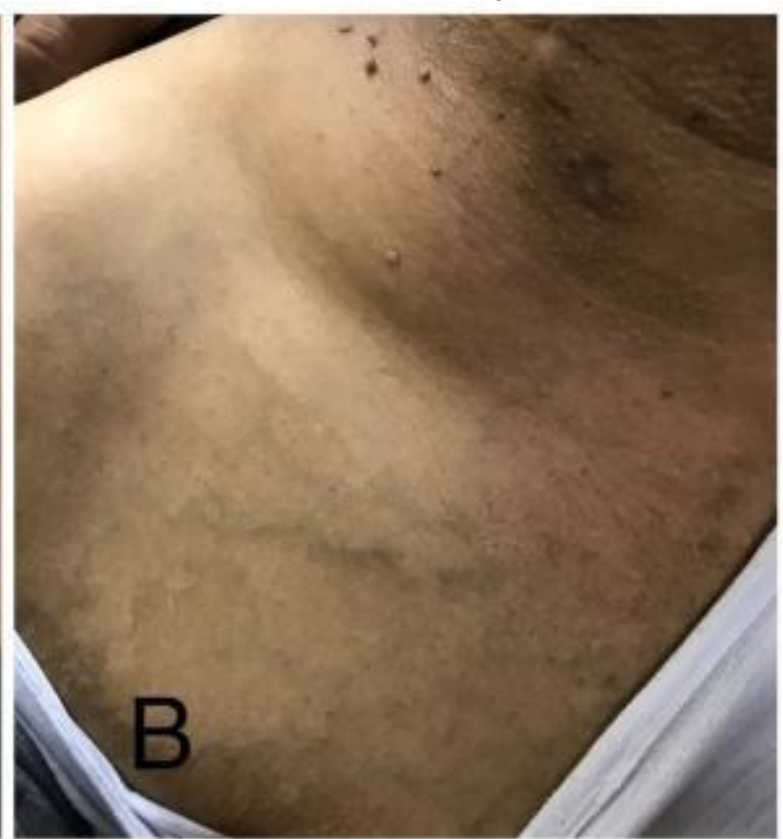

Figure (1): A \& B showed dilated venous collaterals along chest wall denoting significant flow obstruction in axillosubclavian venous segment

Once physical examination suggested the diagnosis, investigations were done starting with plain cervical spine and thoracic inlet X-ray looking for cervical rib, old healed/malunion clavicular fracture and spondylotic changes (Figure 2).
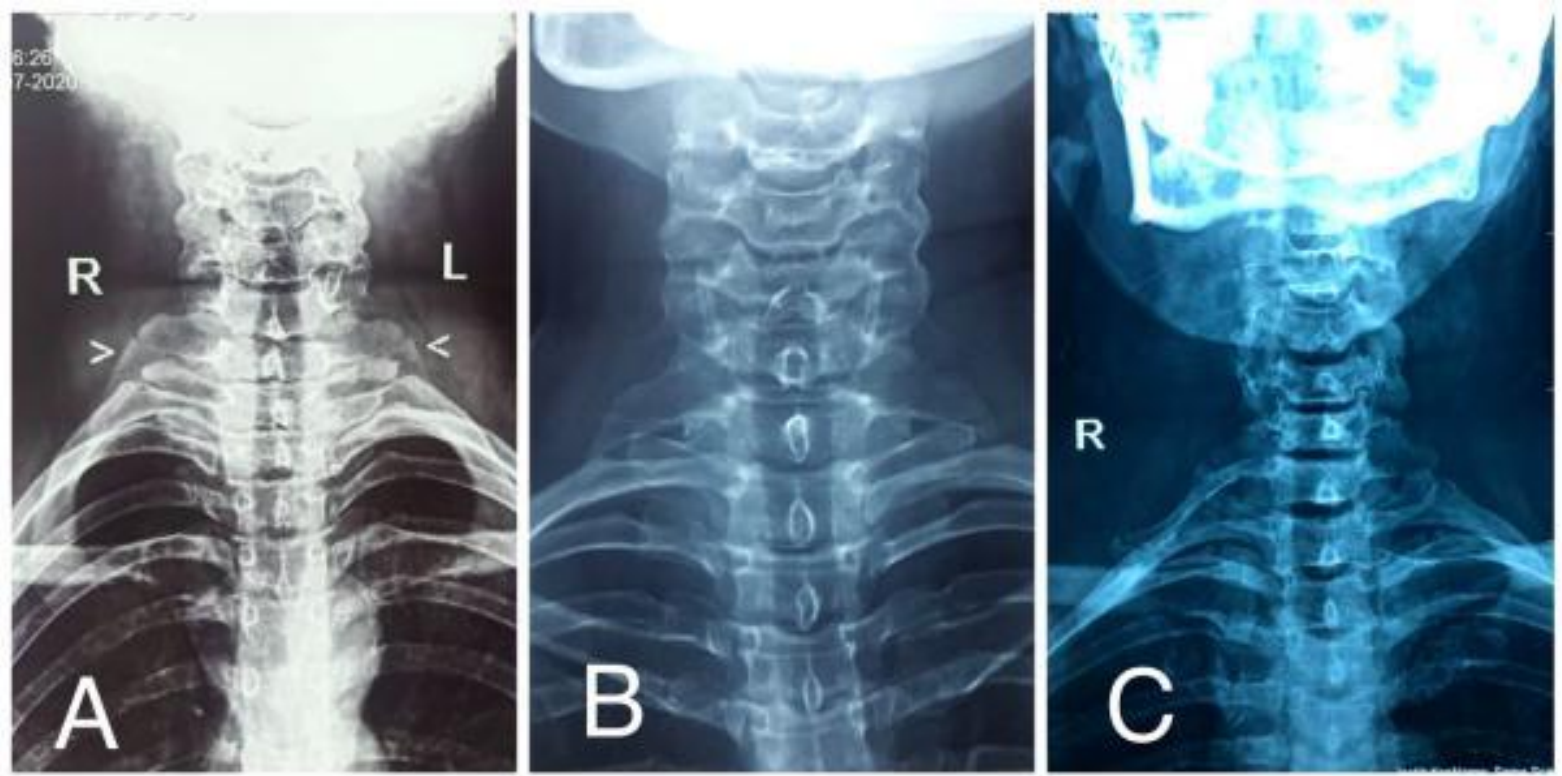

Figure (2): (A) Plain cervical and thoracic inlet X-ray. (B) Bilateral cervical rib. (C) Right-sided cervical rib. 
Duplex ultrasound was done first to exclude acute or chronic thrombotic events then dynamic duplex assessment (evaluation of upper limb venous system in three arm positions neutral, abduction and overhead position) was done looking for venous collaterals, decrease or loss of phasicity of venous flow with stress position. In patients with normal duplex finding, direct CT venography and venous enhanced peak arterial magnetic resonant venography (VEPAMRV) were done to detect axillo-subclavian venous segment attenuation, hypertrophied scalenus anterior and pectoralis minor muscles, as shown in Figure (3).

All included patients were operated upon for complete surgical decompression under general endotracheal anesthesia in supine reversed Trendelenburg position with full neck extension and head rotation to the contralateral side. Our approach through para-clavicular incision and complete surgical decompression included complete first rib resection, scalenectomy, pectoralis minor myomectomy, subclavius muscle and ligament excision with axillo-subclavian segment venolysis (Figure $4 \& 5$ ). Suction drain was inserted routinely in all patients through infraclavicular incision and was removed in fourth postoperative day except in patients who developed lymphorrhea. In studied group (B) axillo-subclavian venous segment venoplasty was done routinely as a part of standard surgical management, it was done either simultaneously with surgical decompression or sequentially at the same hospital admission before discharge (Figure 6). Balloon angioplasty was done through ultrasound guided ipsilateral basilic vein access using 7 and 8F sheath. Angioplasty was accomplished with gradual balloon dilatation with $10 \mathrm{~mm}, 12 \mathrm{~mm}$ up to $14 \mathrm{~mm}$ balloon diameter using Mustang balloon (Boston Scientific, Marlborough, Massachusetts, USA), Conquest Balloon (Bard Peripheral Vascular Inc., Tempe, Arizona, USA) and Advance Enforcer 35 balloon (Cook Medical, Bloomington, Ind, USA). In group (A) axillosubclavian balloon angioplasty was considered as a secondary procedure when there were residual symptoms with partial symptomatic improvement. All patients in postoperative follow-up were given prophylactic anticoagulant therapy in form of LMW heparin 40 IU subcutaneously once daily for a week, all patients were instructed to wear arm compression sleeves form second postoperative day for at least one month postoperatively. Follow-up visits were scheduled once weekly for the first postoperative month then every three months.

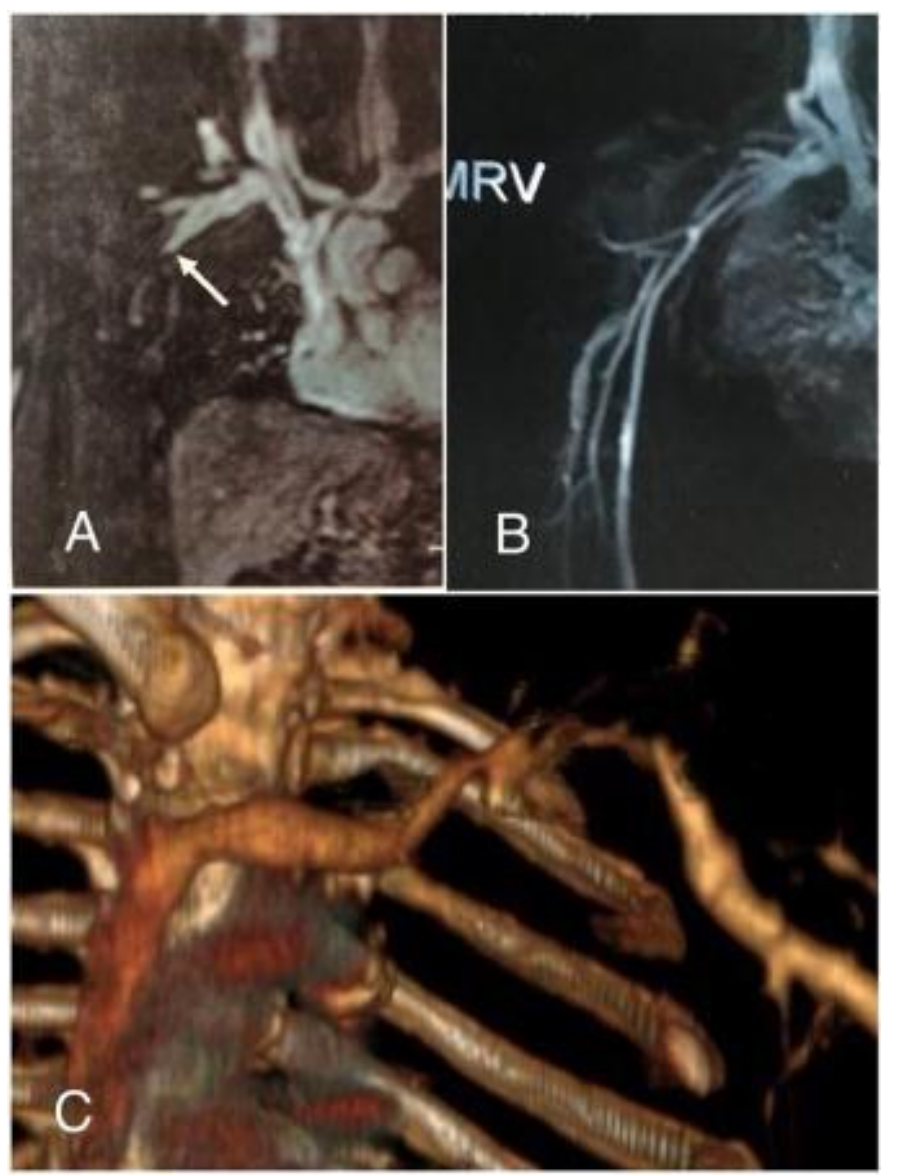

Figure (3): (A) MRV showed significant stenosis of right subclavian vein. (B) VEPAMRV showed attenuation of axillosubclavian venous segment in relation to subclavian artery. (C) Direct CT venography with significant left subclavian vein stenosis at costoclavicular junction after subtraction of sternoclavicular joint. 


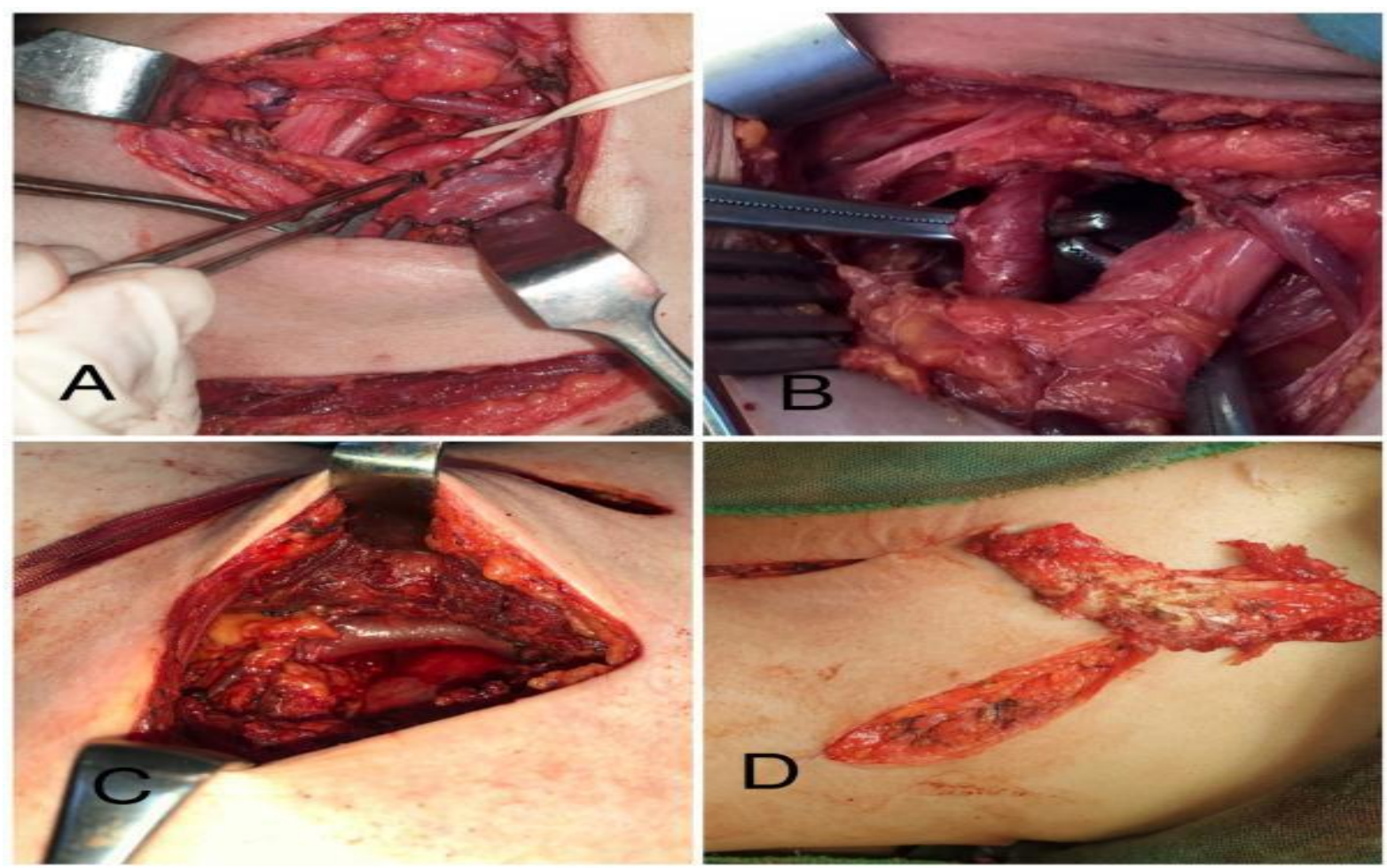

Figure (4): (A) Right paraclavicular skin incision with subclavian artery exposure. (B) Right subclavian artery and left brachial plexus after scalenus anterior and medius resection. (C) Apparently distended subclavian vein after complete decompression and venolysis. (D) Completely resected first rib.
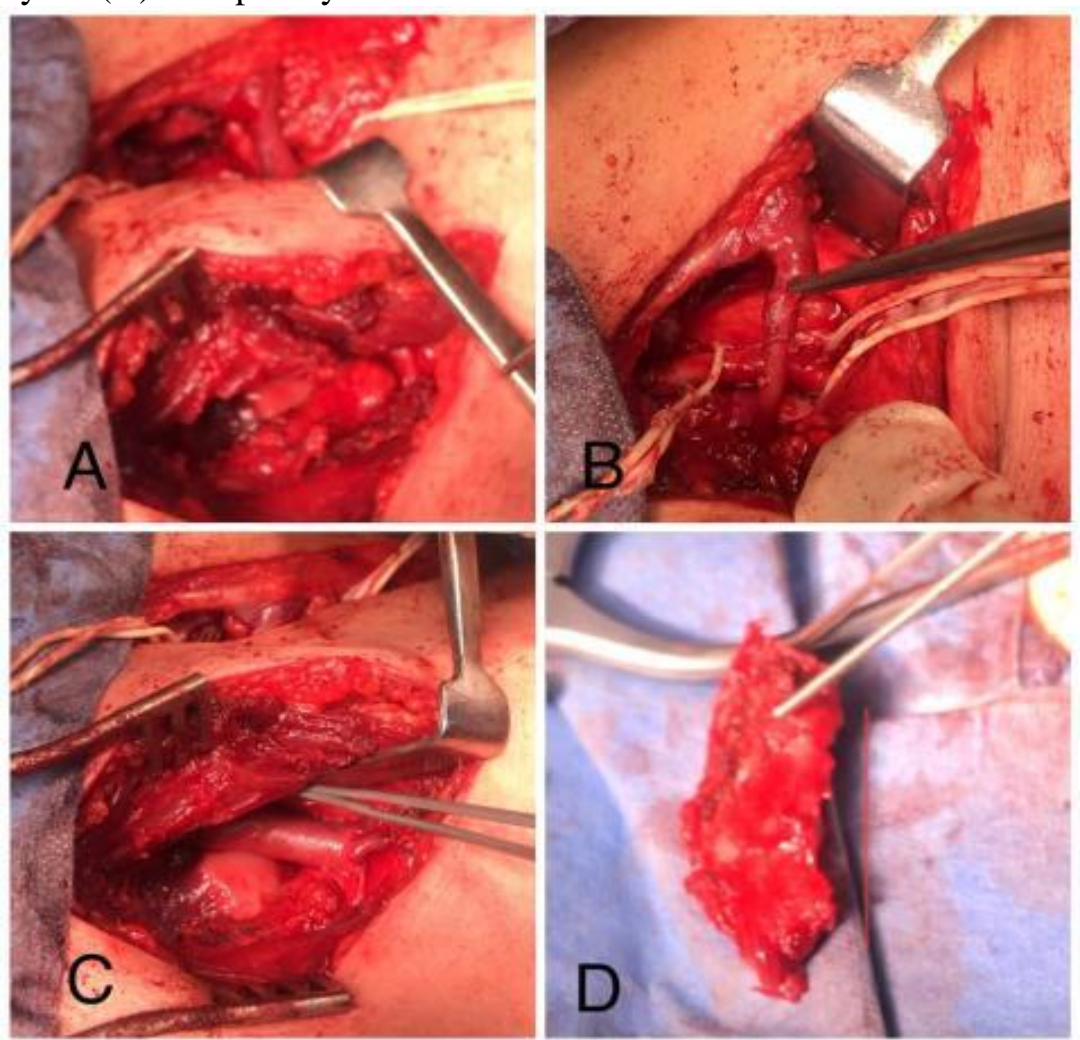

Figure (5): (A) Left paraclavicular incision. (B) Left subclavian artery after scalenus muscle resection with preservation of external jugular vein. (C) Left subclavian vein freely dissected with underlying left lung. (D) Left first rib after resection. 

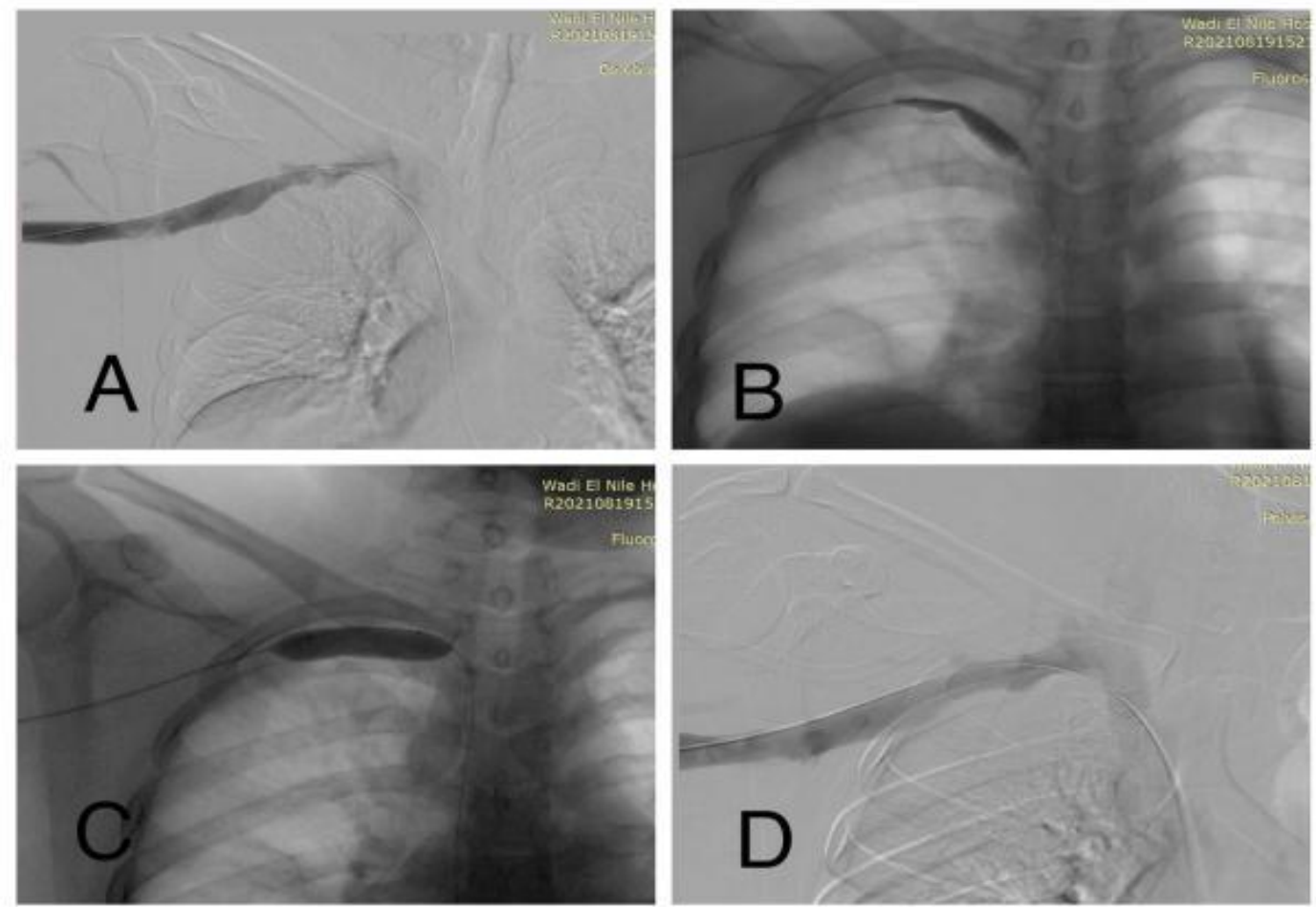

Figure (6): (A) Apparently normal subclavian venous segment after surgical decompression. (B) Significant balloon waist denoting hemodynamically significant stenosis mostly due to luminal synechiae. (C) Optimum balloon angioplasty of subclavian vein (D) Adequate flow in subclavian vein and innominate vein post angioplasty.

\section{Ethical consent:}

An approval of the study was obtained from Benha University and Ain Shams University, Academic and Ethical Committees. Every patient signed an informed written consent for acceptance of the operation. This work has been carried out in accordance with The Code of Ethics of the World Medical Association (Declaration of Helsinki) for studies involving humans.

\section{Statistical methods}

Data management and statistical analysis were conducted using SPSS vs.25. (IBM, Armonk, New York, United States). Numerical data had been summarized as means and standard deviations or medians and ranges. Categorical data were summarized as numbers and percentages. As normality assessment might be invalid due to the small number of patients. Chi square test $(\chi 2)$ to calculate difference between two or more groups of qualitative variables. Quantitative data were expressed as mean \pm SD (Standard deviation). Independent samples t-test was used to compare between two independent groups of normally distributed variables (parametric data). All $\mathrm{P}$ values were two-sided. $\mathrm{P}$ value $\leq 0.05$ was considered significant.

\section{RESULTS}

We identified 23 patients with McCleery's syndrome at the included centers from January 2016 till February 2021. Patients were divided into two groups, group (A): patients who underwent surgical decompression then follow up, and group (B): patients who underwent surgical decompression associated with angiography and balloon angioplasty to the axillosubclavian venous segment. In this cohort, 8 (34.8\%) patients were males while $15(65.2 \%)$ patients were females, the median age was $35.47 \pm 5.22 .4(17.4 \%)$ patients were diabetic, one $(4.3 \%)$ patient was on antihypertensive drug therapy, 7 (30.4\%) patients were smokers, and one $(4.3 \%)$ patient was known to have thrombophilia. Table (1) compares between both groups as regards the demographic data.

Table (2) showed that the right upper limb was affected in $14(60.9 \%)$ patients while the left one was affected in $9(39.1 \%)$ patients. Significant limb edema was observed in $18(78.3 \%)$ patients, heaviness pain was reported by all $23(100 \%)$ patients, bluish discoloration was found in $11(47.8 \%)$ patients, dilated chest wall veins were noticed in $17(73.9 \%)$ patients, associated numbness was complained by $11(47.8 \%)$ patients, and recurrent cellulitis as a complication was diagnosed in 9 $(39.1 \%)$.

Table (1): Demographic data of both groups

\begin{tabular}{|c|c|c|c|}
\hline & $\begin{array}{c}\text { Group (A) } \\
(n=13)\end{array}$ & $\begin{array}{c}\text { Group (B) } \\
(\mathbf{n}=\mathbf{1 0})\end{array}$ & $\begin{array}{c}P \\
\text { value }\end{array}$ \\
\hline Male & $5(38.5 \%)$ & $3(30 \%)$ & \multirow[b]{2}{*}{1.0000} \\
\hline Female & $8(61.5 \%)$ & $7(70 \%)$ & \\
\hline Age & $35.23 \pm 5.39$ & $35.8 \pm 4.97$ & 0.7975 \\
\hline Diabetes & $3(23.1 \%)$ & $1(10 \%)$ & 0.6036 \\
\hline Hypertension & $0(0 \%)$ & $1(10 \%)$ & 0.4348 \\
\hline Smoking & $4(30.8 \%)$ & $3(30 \%)$ & 1.0000 \\
\hline Thrombophilia & $1(7.7 \%)$ & $0(0 \%)$ & 1.0000 \\
\hline
\end{tabular}


Table (2): The symptomatic limb and different clinical presentation

\begin{tabular}{|c|c|c|c|}
\hline & $\begin{array}{l}\text { Group } \\
(\text { A) } \\
(\mathbf{n}=13)\end{array}$ & $\begin{array}{c}\text { Group } \\
(\mathbf{B}) \\
(\mathbf{n}=10)\end{array}$ & \\
\hline Right upper limb & $\begin{array}{c}8 \\
(61.5 \%)\end{array}$ & $6(60 \%)$ & \multirow[t]{2}{*}{1.0000} \\
\hline Left upper limb & $\begin{array}{c}5 \\
(38.5 \%)\end{array}$ & $4(40 \%)$ & \\
\hline Swollen limb & $\begin{array}{c}10 \\
(76.9 \%)\end{array}$ & $8(80 \%)$ & 1.0000 \\
\hline Heaviness & $\begin{array}{c}13 \\
(100 \%)\end{array}$ & $\begin{array}{c}10 \\
(100 \%)\end{array}$ & 1.0000 \\
\hline $\begin{array}{l}\text { Bluish } \\
\text { discoloration }\end{array}$ & $\begin{array}{c}7 \\
(53.8 \%) \\
\end{array}$ & $4(40 \%)$ & 0.6802 \\
\hline $\begin{array}{l}\text { Dilated veins on } \\
\text { the anterior chest } \\
\text { wall }\end{array}$ & $\begin{array}{c}10 \\
(76.9)\end{array}$ & $7(70 \%)$ & 1.0000 \\
\hline Numbness & $\begin{array}{c}7 \\
(53.8 \%)\end{array}$ & $4(40 \%)$ & 0.6802 \\
\hline $\begin{array}{l}\text { Recurrent } \\
\text { cellulitis }\end{array}$ & $\begin{array}{c}5 \\
(38.5 \%) \\
\end{array}$ & $4(40 \%)$ & 1.0000 \\
\hline $\begin{array}{l}\text { Duration of } \\
\text { symptoms }\end{array}$ & $\begin{array}{c}23.38 \\
\pm 7.86 \\
\text { months }\end{array}$ & $\begin{array}{c}22.5 \pm \\
6.70 \\
\text { months }\end{array}$ & 0.7797 \\
\hline $\begin{array}{l}\text { Limb } \\
\text { circumference } \\
\text { discrepancy }\end{array}$ & $\begin{array}{r}2.86 \pm \\
1.13 \mathrm{~cm}\end{array}$ & $\begin{array}{c}2.57 \pm 1.10 \\
\mathrm{~cm}\end{array}$ & 0.5438 \\
\hline
\end{tabular}

Regarding the demographic data and patients' clinical findings, there were no significant difference in both studied groups. Plain cervical radiographs, dynamic duplex ultrasound, CT venography, and MRV were done to diagnose such cases. Table (3) provided a comparison between both groups as regards the findings that led to the diagnosis of such cases.

Table (3): Investigations done for diagnosis

\begin{tabular}{|l|c|c|c|}
\hline & $\begin{array}{c}\text { Group } \\
(\mathbf{A}) \\
(\mathbf{n}=13)\end{array}$ & $\begin{array}{c}\text { Group } \\
(\mathbf{B}) \\
(\mathbf{n}=10)\end{array}$ & \\
\hline $\begin{array}{l}\text { Cervical rib with } \\
\text { plain X-ray }\end{array}$ & $\mathbf{2}$ & $\mathbf{2}$ & $\mathbf{1 . 0 0 0 0}$ \\
$(\mathbf{1 5 . 4 \%})$ & $(\mathbf{2 0 \%})$ & \\
\hline $\begin{array}{l}\text { Positive finding in } \\
\text { dynamic venous } \\
\text { duplex }\end{array}$ & $\mathbf{5}$ & $\mathbf{6}$ & $\mathbf{0 . 4 1 3 6}$ \\
\hline $\begin{array}{l}\text { Positive MRV \& } \\
\text { CTV }\end{array}$ & $\begin{array}{c}\mathbf{1 3} \\
(\mathbf{1 0 0 \%})\end{array}$ & $\begin{array}{c}\mathbf{1 0} \\
(\mathbf{1 0 0 \%})\end{array}$ & $\mathbf{1 . 0 0 0 0}$ \\
\hline
\end{tabular}

In group (A) the primary surgical treatment was complete surgical decompression with secondary axillosubclavian venous segment angioplasty when indicated due to residual symptoms. Complete symptomatic resolution was achieved in 6/13 (46.2\%) patients and secondary endovenous intervention was required in $7(53.8 \%)$ patients due to residual symptoms, postoperative average residual arm circumference difference was $0.92 \pm 0.86 \mathbf{~ c m}$ with a statistically significant difference in favor to group (B)
$(P$ value $=0.0274)$. In group $B$ the primary surgical therapy was combined surgical decompression with completion venous angioplasty that was done simultaneously as hybrid therapy or sequentially in another session at the same hospital admission with complete symptomatic cure in 10/10 (100\%) patients with statistically highly significant difference favoring group $(\mathrm{B})(\mathrm{P}$ value $=0.0075)($ Table 4$)$.

Table (4): Improvement of symptoms at 3 months follow-up

\begin{tabular}{|c|c|c|c|}
\hline & $\begin{array}{c}\text { Group } \\
(\mathrm{A}) \\
(\mathrm{n}=13)\end{array}$ & $\begin{array}{c}\text { Group } \\
(\mathbf{B}) \\
(\mathbf{n}=10)\end{array}$ & \\
\hline $\begin{array}{l}\text { Complete } \\
\text { resolution }\end{array}$ & $\begin{array}{c}6 \\
(46.2 \%)\end{array}$ & $\begin{array}{c}10 \\
(100 \%)\end{array}$ & \multirow[t]{2}{*}{$0.0075 * *$} \\
\hline $\begin{array}{l}\text { Partial } \\
\text { resolution }\end{array}$ & $\begin{array}{c}7 \\
(53.8 \%)\end{array}$ & O & \\
\hline $\begin{array}{l}\text { Residual arm } \\
\text { circumference } \\
\text { difference }\end{array}$ & $\begin{array}{l}0.92 \pm 0.86 \\
\mathrm{~cm}\end{array}$ & $0 \mathrm{~cm}$ & $0.0274 *$ \\
\hline
\end{tabular}

significant result

Postoperative complications as lymphorrhea and seroma were equivalent in both groups except winging of scapula that was documented in $1(4.3 \%)$ patient belonged to group A with no statistically significant difference between both groups (Table 5).

Table (5): postoperative complications

\begin{tabular}{|c|c|c|c|}
\hline & $\begin{array}{c}\text { Group (A) } \\
(n=13)\end{array}$ & $\begin{array}{c}\text { Group (B) } \\
(n=10)\end{array}$ & \\
\hline $\begin{array}{l}\text { Wound } \\
\text { seroma }\end{array}$ & $1(7.7 \%)$ & $1(10 \%)$ & 1.0000 \\
\hline Lymphorrhea & $1(7.7 \%)$ & $1(10 \%)$ & 1.0000 \\
\hline $\begin{array}{l}\text { Winging of } \\
\text { scapula }\end{array}$ & $1(7.7 \%)$ & $0(0 \%)$ & 1.0000 \\
\hline
\end{tabular}

In the patients who did not improve, we did another complementary procedure of axillary and subclavian vein balloon dilatation.

\section{DISCUSSION}

Intermittent subclavian vein outflow obstruction resulting in arm swelling and discoloration of the upper extremity occurring periodically without underlying DVT was first reported in 1939. It was thought subclavius tendon and anterior scalene muscle compression were the main cause of intermittent venous obstruction with symptoms induction by arm abduction (6). Sanders and Hammond ${ }^{(7)}$ reported a group of patients with unilateral arm swelling without thrombosis due to compression of the subclavian vein at the costoclavicular ligament by the ligament or subclavius tendon.

The patients registered in our study were young with a mean age of $35.23 \pm 5.39$ years in group A and $35.8 \pm 4.97$ years in group B with minimal major risk factors. Urschel et al. ${ }^{(8)}$ documented in his manuscript 
that venous TOS usually developed in young, healthy patients with few if any comorbid conditions. The mean age at diagnosis was 32 years, with the majority of patients affected between the second and fourth decades.

In our study, women were affected more than men while the largest series published by Urschel $\boldsymbol{e t}$ al. ${ }^{(8)}$ (312 affected extremities) reported an equal gender ratio. We reported that the right upper limb was affected in $14(60.9 \%)$ patients while the left one was in 9 (39.1\%) patients. Significant limb edema was observed in $18(78.3 \%)$ patients, heaviness pain was reported by all $23(100 \%)$ patients, bluish discoloration was found in $11(47.8 \%)$ patients, dilated chest wall veins were noticed in $17(73.9 \%)$ patients, associated numbness was complained by $11(47.8 \%)$ patients, and recurrent cellulitis as a complication was diagnosed in $9(39.1 \%)$. Visible collateral veins around the shoulder was a common presentation (99\%). Urschel and Patel (9) reported that arm swelling was 96\%, bluish discoloration was $94 \%$, aching pain with exercise was $33 \%$, and cervical ribs were $10 \%$. Only $4 \%$ of the patients presented with minimal symptoms.

We have chosen non-thrombotic obstruction that is why there was difference in the values of clinical symptoms while the study by Urschel and Patel (9) included patients with thrombotic obstruction what is known as Paget- Schroetter syndrome. We started our patient's evaluation with colored duplex due to its availability, simplicity and non-invasive nature as well as being inexpensive modality. All patients in our study were diagnosed by a dynamic duplex. Sanders and Hammond ${ }^{(7)}$ noted that duplex scan was less reliable in monitoring subclavian vein patency, as they expressed difficulty with probe placement and identification of collateral veins upon duplex scan.

Baz (10) showed in his study that venous compression was the predominating type of TOS with venous TOS being found in $84.4 \%$ of the patients. Bilateral affection was also a predominating feature being observed in $94.4 \%$ of the patients. Baz ${ }^{(\mathbf{1 0 )}}$ noticed that most of the compressions took place at the costoclavicular space $(91.3 \%)$.

MRI venography and direct CTV proved to be an attractive diagnostic alternative tool in our study, since it allowed visualization of the veins in a detailed manner, including the subclavian and brachiocephalic segments under the clavicle without risk of radiation exposure. In our cohort evidence of axillo-subclavian venous segment compression was confirmed in 100\% of patients. Remy et al. ${ }^{(11)}$ have demonstrated the utility of direct CTV in evaluation of the upper extremity veins. They demonstrated that reliance on axial slices alone could lead to misrepresentation of the degree of any stenosis. They reported underestimation of stenosis in $43 \%$ of transverse CT scans but only in $10 \%$ of sagittal reconstructions. Overestimation of stenosis was also more frequent on surface displayed with 3-D shading (16\%) than on volume-rendered images (7\%).
Erosy et al. ${ }^{(12)}$ showed that the key finding in MRV is narrowing of the subclavian vein. However, other findings, such as complete occlusion, collateral vessel formation, and visualization of thrombus, helped in the diagnosis of venous TOS. Interestingly, all patients with arterial compression were found to have venous compression during arm abduction. In patients with venous compression on one side, $71 \%$ had significant bilateral venous compression. Of these patients with bilateral imaging findings, only $21 \%$ had bilateral clinical symptoms or findings suggestive of TOS. Therefore, MRV had the potential to over diagnose venous TOS, and clinical symptoms must be taken into account.

In our study, we also found that compression of the axillo-subclavian venous segment without thrombosis can be present for a long period of time. Patients of our study were treated with two surgical strategies complete surgical decompression was the common therapy in both groups while endovenous angioplasty was a part of standard treatment in group (B). We found that axillosubclavian venous segment angioplasty significantly improved the outcome of surgical decompression in favoring to group (B). This may be explained by traumatic injury to this venous segment by prolonged repetitive arm movements causing post-traumatic inflammatory process, focal intimal fibrosis, stenosis, and blood flow stasis due to internal synechiae, these represent the hidden cause of residual symptoms in case of group (A). That is why symptom improvement in case of completion angioplasty confirms our rationale of adding venous angioplasty as a part of standard treatment. de León et al. ${ }^{(13)}$ analysed 67 patients with venous TOS of them $11(16 \%)$ patients were presenting with McCleery syndrome at an average of 57 weeks after occurrence of symptoms. All 11 patients had no venous thrombosis but had upper extremity swelling. Upon duplex scan, all patients demonstrated vein occlusion with abduction of the upper extremity. Eleven first rib resection procedures were performed in this patient subset, and 3 patients underwent postoperative venogram due to persistent symptoms. Of these patients, 2 required dilatation at the time of the venogram, and the other demonstrated a widely patent vein. Surgical decompression of the thoracic outlet yielded relief of symptoms in all $11(100 \%)$ patients.

\section{CONCLUSION}

Completion vein angioplasty of surgically decompressed axillosubclavian venous segment added a significant benefit to FRRS reflected on complete symptoms cure without adding any risk for patients with McCleery's syndrome. It could be considered as a primary therapy in conjunction with surgical decompression. Multiple prospective comparative studies are required to confirm our results and standardize our treatment strategy. 
Financial support and sponsorship: Nil.

Conflict of interest: Nil.

\section{REFERENCES}

1. Illig K, Doyle A (2010): A comprehensive review of Paget-Schroetter syndrome. J Vasc Surg., 51:1538-47.

2. Pesser N, Bode A, Goeteyn J et al. (2021): Same Admission Hybrid Treatment of Primary Upper Extremity Deep Venous Thrombosis with Thrombolysis, Transaxillary Thoracic Outlet Decompression, and Immediate Endovascular Evaluation. Ann Vasc Surg., 71: 249-256.

3. Moore R, Wei Lum Y (2015): Venous thoracic outlet syndrome. Vasc Med., 20 (2): 182-189.

4. Likes K, Rochlin D, Call D et al. (2014): McCleery syndrome: etiology and outcome. Vasc Endovascular Surg., 48 (2):106-10.

5. Illig K, Donahue D, Duncan A et al. (2016): Reporting standards of the Society for Vascular Surgery for thoracic outlet syndrome. J Vasc Surg., 64 (3): 23-35.

6. AbuRahma A (1991): Conventional versus thrombolytic therapy in spontaneous (effort) axillarysubclavian vein thrombosis. Am J Surg., 161: 459- 465.
7. Sanders R, Hammond S (2005): Subclavian vein obstruction without thrombosis. J Vasc Surg., 41 (2): 285-290.

8. Urschel H, Razzuk M (2000): Paget-Schroetter syndrome: what is the best management? Ann Thorac Surg., 69 (6): 1663-8.

9. Urschel H, Patel A (2008): Surgery remains the most effective treatment for Paget-Schroetter syndrome: 50 years' experience. Ann Thorac Surg., 86: 254-60.

10. Baz A (2019): An overview of the findings of dynamic upper limbs' arterial and venous duplex in cases of vascular thoracic outlet syndrome. Egyptian Journal of Radiology and Nuclear Medicine, 50: 76-79.

11. Remy-Jardin M, Remy J, Masson P et al. (2000): CT angiography of thoracic outlet syndrome: evaluation of imaging protocols for the detection of arterial stenosis. J Comput Assist Tomogr., 24 (3): 349-61.

12. Ersoy H, Steigner M, Coyner K et al. (2012): Vascular thoracic outlet syndrome: protocol design and diagnostic value of contrast-enhanced 3D MR angiography and equilibrium phase imaging on 1.5- and 3-T MRI scanners. AJR Am J Roentgenol., 198 (5): 1180-7.

13. de León R, Chang D, Hassoun H et al. (2009): Multiple treatment algorithms for successful outcomes in venous thoracic outlet syndrome. Surgery, 145 (5): 500-7. 